JOURNAL OF E-ISSN 2656-3436/ P-ISSN 2615-3947

BIOLOGY IAIN KUDUS

O B E EDUCATION Tersedia online: http://journal.iainkudus.ac.id/index.php/jbe

\title{
Tingkat Kemampuan Berpikir Kritis Guru Biologi Kota Pekanbaru
}

\author{
Febblina Daryanes ${ }^{1 *}$, Riki Apriyandi Putra ${ }^{2}$ \\ 1,2) Program Studi Pendidikan Biologi, FKIP Universitas Riau \\ febblina.daryanes@lecturer.unri.ac.id
}

\begin{abstract}
ABSTRAK
Berpikir kritis merupakan salah satu aspek berpikir yang digunakan dalam mengatasi permasalahan dan menfasilitasi penemuan informasi yang tepat baik melalui proses analisis, interpretasi, evaluasi, inferensi dan pembuktian. Penelitian ini bertujuan untuk mendeskripsikan tingkat kemampuan berpikir kritis para guru Biologi SMA Negeri di Kota Pekanbaru. Populasi pada penelitian ini yaitu semua guru Biologi SMA Negeri Kota Pekanbaru yang berjumlah 62 orang dengan teknik pengambilan sampel yang digunakan adalah sampling jenuh. Data dikumpukan dengan menggunakan kuesioner dan pedoman wawancara, kuesioner disusun berdasarkan 5 indikator berpikir kritis yang dikembangkan oleh Marzano. Data kuesioner dianalisis dengan cara menghitung persentase kemudian dilakukan interpretasi menjadi beberapa kategori, sedangkan hasil wawancara dianalisis secara kualitatif. Hasil penelitian menunjukkan bahwa tingkat keterampilan berpikir kritis Guru Biologi SMA Negeri Kota Pekanbaru sebesar 88.2\% dengan persentase tertinggi pada indikator "akurat dan mencari akurasi" yaitu sebesar $92,5 \%$ berada pada kategori sangat baik sedangkan indikator terendah yaitu "jelas dan mencari kejelasan" dengan persentase sebesar $84,3 \%$ berada pada kategori baik. Dari hasil penelitian dapat disimpulkan bahwa tingkat berpikir kritis Guru Biologi SMA Negeri Kota Pekanbaru berada pada kategori sangat baik.
\end{abstract}

Kata kunci: Berpikir Kritis, Guru, Biologi

\section{ABSTRACT}

Critical thinking is one aspect of thinking that is used in overcoming problems and facilitating the discovery of appropriate information through the process of analysis, interpretation, evaluation, inference and proof. This study aims to describe the level of critical thinking skills of Biology teachers in SMA Negeri in Pekanbaru City. The population in this study were all Biology teachers in Pekanbaru City Senior High School, amounting to 62 people. The sampling technique used was saturated sampling. Data was collected using questionnaires and interview guidelines, the questionnaire was compiled based on 5 critical thinking indicators developed by Marzano. The questionnaire data was analyzed by calculating the percentage and then interpreted into several categories, while 
the results of the interviews were analyzed qualitatively. The results showed that the level of critical thinking skills of Biology Teachers in Pekanbaru City Senior High School was $88.2 \%$ with the highest percentage on the indicator "accurate and seeking accuracy" which was $92.5 \%$ in the very good category while the lowest indicator was "clear and seeking clarity" with the percentage of $84.3 \%$ is in the good category. From the results of the study, it can be concluded that the level of critical thinking of Biology Teachers in Pekanbaru City Senior High School is in the very good category.

Keywords: Critical Thinking, Teacher, Biology

\section{PENDAHULUAN}

Besarnya tantangan pada Abad-21 ini membuat sistem pendidikan di dunia harus dapat beradaptasi dengan cepat. Keterampilan abad 21 yang sangat dibutuhkan tidak hanya dalam proses pembelajaran tetapi dalam memecahkan permasalahan kehidupan. Kemampuan berpikir kritis yang merupakan salah satu indikator keterampilan abad-21 menjadi sorotan dunia dan sangat diperlukan dalam kehidupan (Amin, Duran Corebima, Zubaidah, \& Mahanal, 2017; Nisa, Nafiah, \& Wilujeng, 2020; Puspita, Kaniawati, \& Suwarma, 2017). Demirhan \& Köklükaya (2014) mengatakan bahwa penting setiap warga Negara untuk mengembangkan kebiasaan mandiri dan berpikir kritis. Salah satu tujuan utama pendidikan adalah mendidik warga Negara agar memiliki kemampuan berpikir kritis melalui praktik implementasi pembelajaran dengan berbagai metode ataupun strategi yang diterapkan (Laelasari, Sari, \& Nuhaya, 2019). Bahkan sistem pendidikan di Turki merevisi kurikulum untuk menekankan pada peningkatan kemampuan berpikir kritis (Aktaş \& Ünlü, 2013). Di Negara Iran, semua anggota profesi harus mudah beradaptasi dengan perkembangan dan inovasi untuk meningkatkan kualitas dan profesionalisme, untuk itu system pendidikan menginternalisasikan gagasan dasar dan menyesuaikan dengan proses pembelajaran yang memungkinkan penggunaan pemikiran kritisnya (Gezer, Kantek, \& Öztürk, 2010). Bahkan perawatpun harus menggunakan pemikiran kritisnya untuk merawat pasien secara optimal sehingga semua aspek sangat membutuhkan kemampuan berpikir kritis (Gezer et al., 2010; Hundial, 2020).

Keterampilan berpikir kritis mencerminkan sebuah proses pemikiran yang reflektif, logis, rasional, menginterpretasikan, dan mengumpulkan informasi dalam membuat sebuah keputusan (Demirhan \& Köklükaya, 2014; Puspita et al., 2017). Kemampuan berpikir kritis 
sangat penting untuk dapat dikendalikan oleh semua orang agar dapat melindungi dan memecahkan permasalahan serta menemukan solusi dengan tepat (Amin et al., 2017; Arafah, Abdullah, \& Malago, 2021; Aripin, Setiawan, \& Hendriana, 2019; Laelasari \& Anggraeni, 2017; Puspita et al., 2017). Melalui kemampuan berpikir kritis seseorang akan dapat bertanya dengan tepat, mengatur informasi dengan relevan, efektif dan efisien, membuat kesimpulan dengan benar (Amin et al., 2017). Kemampuan berpikir kritis juga berperan dalam peningkatan kemampuan praktik dan pengetahuan (Cohen, 2010). Hal tersebut menunjukkan bahwa kemampuan berpikir kritis penting untuk diperhatikan dari segala aspek yang berkemungkinan dalam perkembangan (Laelasari \& Hilmi Adisendjaja, 2018). Berpikir kritis menjadi salah satu primadona dalam sebuah kajian penelitian karena pentingnya kemampuan berpikir kritis tidak hanya dalam aspek pendidikan tetapi pada setiap aspek kehidupan.

Seorang guru sangat berperan penting dalam mengembangkan kemampuan berpikir kritis siswa. Menurut Juhji \& Suardi (2018), seorang guru harus memiliki kemampuan kritis, jiwa kreatif, dan komitmen yang tinggi untuk mengembangkan intelegensi dan kemampuan berpikir kritis siswa. Permasalahan di Indonesia bahwa kemampuan berpikir kritis siswa masih lemah (Amin et al., 2017; Arafah et al., 2021; Nisa et al., 2020; Puspita et al., 2017), sehingga kondisi yang berkaitan dengan berpikir kritis perlu menjadi sorotan dalam studi penelitian yang tidak hanya ditinjau dari perspektif siswa tetapi juga dari tingkat kemampuan berpikir kritis guru. Menurut Bezanilla et al. (2019) adanya hubungan antara kerangka cara pandang kemampuan berpikir kritis guru dengan pengembangan kemampuan berpikir kritis siswa.

Pada umumnya penelitian yang telah dilakukan hanya berfokus pada kemampuan berpikir kritis para siswa, diantaranya penelitian yang dilakukan oleh Sk \& Halder (2020) mengenai hubungan berpikir kritis dengan kecerdasan emosional. Penelitian yang dilakukan oleh Chan (2019) mengenai peran sebuah media digital berupa cerita dongeng yang dimanfaatkan untuk mengembangkan kemampuan berpikir kritis siswa. Penelitian Hundial (2020) dan Rahman et al., (2021) mengenai sebuah kerangka pendekatan konstruktivis dalam mengembangkan kemampuan berpikir kritis siswa. Selanjutnya Alexandra \& Ratu (2018), Wiyoko (2019), Rahman et al. (2018) Supriyati et al. (2018), 
Aktaş \& Ünlü (2013) dan Demirhan \& Köklükaya (2014), melakukan penelitian yang berkaitan dengan profil kemampuan berpikir para siswa.

Berdasarkan review penelitian terdahulu sangat sedikit penelitian yang bertitik tolak pada tingkat berpikir kritis guru sebagai pendidik dalam proses pembelajaran, padahal guru merupakan penggerak bagi siswanya. Aliakbari \& Sadeghdaghighi (2013) dalam tulisannya menyatakan bahwa tidak hanya siswa tetapi guru juga perlu diidentifikasi bagaimana tingkat kemampuan berpikir kritisnya, karena pendidikan yang dikomandoi oleh guru dengan kemampuan berpikir kritis yang baik akan lebih mungkin melatihkan dan menularkan kemampuan berpikir kritisnya kepada siswa dibandingkan dengan guru yang tidak memiliki kemampuan berpikir kritis. Keprofesionalan guru dalam mengajar tentu saja juga dipengaruhi dari cara mereka berpikir dan menggunakan pikiran tingkat tinggi mereka. Seorang guru bak investor yang menanamkan kemampuan berpikir kritis pada setiap siswanya sehingga sangat penting melakukan analisis kemampuan berpikir kritis guru yang merupakan seseorang yang berperan aktif dalam dunia pendidikan. Menurut Gezer et al. (2010) dan Alwadai (2014) bahwa kemampuan berpikir kritis dapat ditingkatkan melalui pendidikan dan sangat berkaitan dengan kemampuan berpikir kritis gurunya. Hal tersebut juga didukung dari hasil penelitian yang dilakukan oleh Arafah et al. (2021) Raikou et al., (2017), bahwa guru menyajikan beragam praktik didalam kelas yang didasarkan pada kemampuan pola pikirnya.

Berdasarkan pendapat Cáceres et al. (2020) bahwa sangat besar pengaruh tingkat berpikir guru terhadap kegiatan yang dilakukan guru didalam kelas serta cara guru menghubungkan dan mengembangkan kondisi dan fenomena yang ada. Guru mencoba mengembangkan kemampuan berpikir kritis mereka dengan mengintegrasikannya kedalam pembelajaran. Berdasarkan uraian diatas, peneliti tertarik untuk melakukan penelitian mengenai tingkat berpikir kritis para guru Biologi SMA yang ada di Kota Pekanbaru. Penelitian ini bertujuan untuk mendeskripsikan tingkat kemampuan berpikir kritis para guru Biologi tingkat SMA Negeri di Kota Pekanbaru dengan memperhatikan indikator berpikir kritis menurut Marzano (1994). Hal tersebut juga merupakan poin yang menjadi pembeda dengan penelitian terdahulu yang mayoritas tidak menggunakan indikator berpikir kritis yang dikembangkan oleh Marzano. Menurut Marzano (1994), kemampuan berpikir kritis 
akan membantu seseorang untuk dapat meningkatkan keakurasian dan kejelasan sesuatu hal atau tindakan, berpikiran terbuka, mengungkapkan ide-ide baru, sensitif terhadap kemampuan orang lain. Raikou et al. (2017) mengatakan bahwa disaat seorang guru tidak memiliki kemampuan berpikir kritis yang baik maka mereka tidak akan mampu memandu, menyajikan, membangun dan menciptakan kerangka pembelajaran yang dapat melatih kemampuan berpikir kritis siswa sehingga siswa tidak difasilitasi untuk mengembangkan kemampuan berpikir kritisnya.

\section{METODE PENELITIAN}

Penelitian ini merupakan penelitian deskriptif yang bertujuan untuk melihat tingkat berpikir kritis para guru Biologi SMA Negeri Kota Pekanbaru. Penelitian dilakukan di kota Pekanbaru, tepatnya pada MGMP Guru Biologi SMA Negeri Kota Pekanbaru. Populasi pada penelitian ini yaitu semua guru Biologi SMA Negeri Kota Pekanbaru. Teknik pengambilan sampel yang digunakan adalah sampling jenuh. Menurut Sugiyono (2014), bahwa: "teknik sampling jenuh merupakan teknik penentuan sampel bila semua anggota populasi digunakan sebagai sampel." Jumlah sampel sebanyak 62 guru biologi SMA Negeri Kota Pekanbaru.

Data dikumpukan dengan menggunakan kuesioner dan pedoman wawancara, yang disusun berdasarkan 5 indikator berpikir kritis yang dikembangkan oleh Marzano, yaitu 1) Akurat dan mencari akurasi, 2) Jelas dan mencari kejelasan, 3) Berpikiran terbuka, 4) Mengemukakan ide/gagasan, 5) Bersifat sensitif dan tahu kemampuan teman. Kuesioner menggunakan skala Likert yang dimodifikasi dengan 4 pilihan jawaban. Sebelum instrumen digunakan dalam penelitian, maka dilakukan validasi kepada expert judgment, dosen atau pakar dibidang psikologi. Data kuesioner dianalisis secara kuantitatif dan kualitatif, dan untuk data hasil wawancara dianalisis secara kualitatif. Data mengenai kemampuan berpikir kritis responden yang telah dikumpulkan melalui angket selanjutnya dianalisis. Untuk tiap item pernyataan pada angket terdiri dari empat pilihan skor. Analisis data dilakukan dengan cara menghitung persentase berdasarkan skor yang telah dipilih oleh guru untuk seluruh item kemudian dilakukan interpretasi menjadi beberapa kategori. Kategori baik sekali (86- 
100\%), kategori baik (76-85\%), kategori cukup (60-75\%), kategori kurang (55-59\%) dan kategori kurang sekali ( $\leq 54 \%)$ (Purwanto, 2013).

\section{HASIL DAN PEMBAHASAN}

Hasil penelitian yang diperoleh mengenai tingkat kemampuan berpikir kritis guru Biologi SMA Negeri kota Pekanbaru dapat diketahui bahwa tingkat kemampuan berpikir kritis guru Biologi SMA Negeri Kota Pekanbaru sebesar $88.2 \%$ berada pada kategori sangat baik (Gambar 1.). Berpikir kritis merupakan kemampuan yang penting yang dimiliki oleh seorang guru karena menurut Gezer et al., (2010) dan Fatmawati et al., (2019), berpikir kritis merupakan salah satu cara berpikir yang berfungsi dalam mengakses informasi, menciptakan informasi dan pemecahan masalah serta merupakan aspek berpikir yang sangat penting yang menentukan kesuksesan cara berpikir seseorang. Kemampuan berpikir kritis merupakan keterampilan yang paling berharga yang dapat diturunkan oleh sekolah khususnya guru kepada lulusannya dan menjadi tujuan pembelajaran pada semua tingkat disiplin ilmu. Hal tersebut sejalan dengan pendapat Amin et al., (2017) bahwa guru merupakan faktor utama yang mendukung keterampilan berpikir kritis siswanya.

Menurut Fatmawati et al., (2019), berpikir kritis berkaitan dengan norma, opini, dan tindakan yang mencerminkan nilai, persepsi, dan aktivitas yang menjadi keyakinan. Tingkat kemampuan berpikir kritis guru yang berada pada kategori sangat baik tentunya mendukung proses berpikir yang tajam, cepat, dan akurat. Guru yang memiliki kemampuan berpikir kritis yang baik dapat menciptakan proses pembelajaran yang inovatif, hal ini sesuai dengan yang dikemukakan oleh Demirhan \& Köklükaya, (2014), bahwa semua hal yang kita lakukan dan hasilkan bergantung pada kemampuan berpikir kita. Menurut Bezanilla et al. (2019), strategi pengajaran studi kasus, proyek, berbasis masalah, penyelidikan, dan pembelajaran kontekstual merupakan strategi yang berhubungan dengan kemampuan berpikir kritis. Berdasarkan hasil wawancara, sebagian besar guru-guru Biologi SMA Negeri Kota Pekanbaru memang telah menerapkan proses pembelajaran berbasis masalah, penyelidikan (inkuiri) serta pendekatan saintifik dalam pembelajaran Biologi. Penelitian yang telah dilakukan oleh Daryanes et al. (2016) juga menunjukkan 
bahwa tahapan pembelajaran berbasis pada masalah berkaitan dengan kemampuan berpikir kritis.

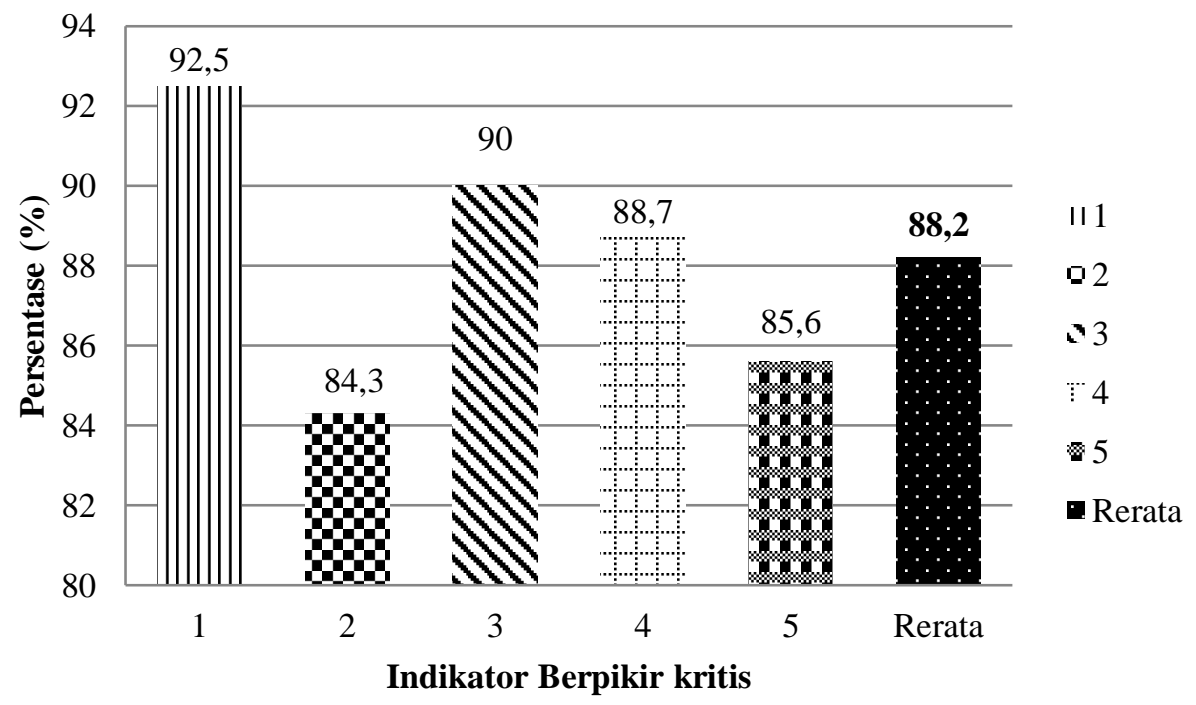

Keterangan: 1) Akurat dan mencari akurasi, 2) Jelas dan mencari kejelasan, 3) Berpikir terbuka, 4) Mampu Mengemukakan ide/gagasan, 5) bersifat sensitif dan tahu kemampuan pengetahuan temannya

Gambar 1. Tingkat kemampuan berpikir kritis guru Biologi SMA N Kota Pekanbaru

Tingkat kemampuan berpikir kritis dapat ditilik dari capaian setiap indikator kemampuan berpikir kritis. Gambar 1. menunjukkan bahwa persentase indikator 1 pada kemampuan berpikir kritis yaitu "akurat dan mencari akurasi" mencapai 92,5\% dan berada pada kategori sangat baik. Hal tersebut menunjukkan bahwa guru-guru telah senantiasa memperhatikan secara rinci semua pekerjaannya, mengecek berbagai sumber untuk penyelesaian tugasnya, semua tugas mereka lengkap dan akurat serta guru-guru melakukan perbaikan dengan segera saat ditemukan kesalahan pada tugas yang dikerjakan. Berdasarkan wawancara juga diperoleh informasi bahwa setiap ada tugas yang diberikan maka guru selalu berusaha mencari berbagai sumber informasi dari internet, selalu memperhatikan secara rinci tugas yang diberikan dan saling sharing informasi dengan teman agar ketika ada kesalahan pada tugas mereka dapat langsung memperbaikinya. Dalam proses pembelajaran juga guru-guru selalu mengarahkan siswa untuk selalu menggunakan berbagai sumber informasi untuk mendapatkan hasil yang akurat, guru selalu 
membimbing siswa dalam merinci setiap tahap pada proses pengerjaan tugas agar siswa juga terbiasa untuk selalu menganalisis tugas-tugasnya. Hal tersebut sesuai dengan yang dikemukakan oleh Cohen (2010) dalam karya ilmiahnya yaitu, seseorang yang memiliki sifat selalu mencari keakurasian maka ditandai dengan sikap mencari informasi terbaik dalam situasi, kondisi, atau masalah tertentu. Seseorang yang selalu mencari informasi tambahan baik yang berkaitan dengan fakta, opini, dan perspektif yang baru maka akan selalu melakukan penyelidikan untuk melengkapi informasi yang ada.

Indikator 2 kemampuan berpikir kritis yaitu "jelas dan mencari kejelasan", persentase tingkat capaian indikator tersebut sebesar $84,3 \%$ berada pada kategori baik. Menurut penelitian Idris, (2018) indikator 1 pada kemampuan berpikir kritis yaitu akurat dan mencari akurasi memiliki hubungan dengan indikator 2 yaitu jelas dan mencari kejelasan, yang mana hasil penelitiannya menunjukkan tingkat capaian indikator 1 dan 2 pada mahasiswa sama-sama berada pada kategori cukup. Hal tersebut berbeda dengan fakta yang diperoleh dalam penelitian ini yang tingkat capaian pada indikator 1 berada pada kategori sangat baik sedangkan tingkat capaian indikator 2 berada pada kategori baik. Hasil yang diperoleh ini membuat peneliti melakukan wawancara mendalam pada beberapa orang guru dari sampel penelitian yang memilih poin maksimal pada indikator 1 dan pada indikator 2 memilih kurang maksimal. Berdasarkan wawancara diperoleh informasi bahwa sebagian besar guru-guru memang selalu memperhatikan secara rinci tugas yang diberikan dan selalu mencari berbagai sumber informasi misalnya dari internet dalam menyelesaikan tugas dan selalu berusaha mencari keakurasian tetapi masih ada guru yang hasil kerjanya membingungkan walaupun mereka sudah berusaha mencari dari berbagai sumber informasi, sehingga tingkat capaian pada indikator 1 yaitu akurat dan mencari akurasi berada pada kategori sangat baik tetapi tingkat capaian pada indikator 2 yaitu jelas dan mencari kejelasan berada pada kategori baik. Akan tetapi tingkat capaian indikator 2 masih berada pada kategori baik walaupun tidak setinggi capaian pada indikator 1.

Indikator 3 dalam kemampuan berpikir kritis yaitu "berpikir terbuka" dengan tingkat capaian indikator berada pada kategori sangat baik yaitu sebesar 92\%. Hal tersebut menunjukkan bahwa berpikiran terbuka dalam menerima ide-ide baru, tanggapan atau solusi dari guru lainnya demi dapat menyelesaikan suatu permasalahan ataupun tugas. 
Menurut Nurmaulita, (2014), seseorang yang tidak berpikiran terbuka ditunjukkan dengan sikap egois yang tinggi, kurang menyadari kelemahan dan tidak mau menerima ide atau pendapat orang lain. Berdasarkan hasil wawancara guru-guru selalu aktif dalam kegiatan Musyawarah Guru Mata Pelajaran (MGMP) sehingga mereka sudah memiliki wadah tempat berdiskusi dan berbagi ilmu. Pada kegiatan tersebut guru-guru saling berdiskusi mengenai materi pembelajaran, perangkat pembelajaran, strategi pembelajaran yang baik untuk meningkatkan proses pembelajaran. Guru-guru mengatakan dengan saling berbagi banyak wawasan yang bisa dikembangkan dengan lebih baik lagi dan akan menciptakan pemikiran yang lebih aktual. Guru-guru juga memiliki grup whatsapp untuk berbagi informasi sehingga mereka sudah terbiasa berpikir terbuka dalam berbagai hal.

Indikator 4 dalam kemampuan berpikir kritis yaitu "mampu mengemukakan ide/gagasan", pada indikator ini tingkat capaiannya juga berada pada kategori sangat baik sama halnya dengan indikator 1 dan 3, yaitu sebesar 88,7\%. Hal tersebut menunjukkan bahwa guru-guru senantiasa mengemukakan ide atau pendapatnya dalam menyelesaikan suatu permasalahan. Guru-guru juga senantiasa menerapkan sikap demokratis dalam proses diskusi antar sesama guru di lingkungan sekolah maupun diskusi dalam group whatsapp. Semua guru diberi kesempatan untuk mengemukakan ide dan gagasannya dan menerima ide serta pendapat orang lain, hal tersebut juga melatihkan untuk berani mengemukakan ide atau gagasannya dalam proses pembelajaran. Hal ini sejalan dengan hasil penelitian Chan (2019) bahwa kegiatan berdialog dan berdiskusi dapat mendukung keterlibatan diri dalam mengembangkan pola berpikir kritis yang dapat membangun dan meningkatkan kualitas cara berpikir.

Indikator 5 pada kemampuan berpikir kritis yaitu, "bersifat sensitif dan tahu kemampuan temannya" berada pada tingkat capaian $85,6 \%$ kategori baik. Guru-guru cukup memahami perasaan temannya dan memahami bahwa pengetahuan dan kemampuan setiap orang berbeda-beda, seperti yang dikemukakan oleh Hundial (2020) bahwa setiap orang memiliki kemampuan yang berbeda-beda. Setiap guru memiliki sense terhadap orang lain atau temannya, guru-guru memiliki empati terhadap temannya karena seringnya mereka berinteraksi. Berdasarkan hasil wawancara diketahui bahwa guru-guru selalu memahami kondisi dan situasi saat akan berkomunikasi terhadap temannya, guru-guru juga saling 
berkoordinasi dengan yang lainnya saat berada diruang guru ataupun saat berkumpul bersama sehingga tidak ada guru yang apatis.

\section{SIMPULAN}

Berdasarkan hasil penelitian dapat disimpulkan bahwa tingkat keterampilan berpikir kritis Guru Biologi SMA Negeri Kota Pekanbaru sebesar 88.2\% berada pada kategori sangat baik. Indikator "akurat dan mencari akurasi" dari kemampuan berpikir kritis merupakan indikator dengan capaian tertinggi yaitu sebesar 92,5\% dengan kategori sangat baik, lalu diikuti dengan indikator "berpikiran terbuka", "mampu mengemukakan ide/gagasan", "sensitif dan tahu kemampuan teman", serta "jelas dan mencari kejelasan" dengan capaian persentase berturut-turut sebesar 90\% (sangat baik), 88,7\% (sangat baik), $85,6 \%$ (baik), dan $84,3 \%$ (baik).

\section{DAFTAR PUSTAKA}

Aktaş, G. S., \& Ünlü, M. (2013). Critical Thinking Skills of Teacher Candidates of Elementary Mathematics. Procedia - Social and Behavioral Sciences, 93(1), 831-835. https://doi.org/10.1016/j.sbspro.2013.09.288

Alexandra, G., \& Ratu, N. (2018). Profil Kemampuan Berpikir Kritis Matematis Siswa SMP Dengan Graded Response Models. Mosharafa: Jurnal Pendidikan Matematika, 7(1), 103-112.

Aliakbari, M., \& Sadeghdaghighi, A. (2013). Teachers' Perception of the Barriers to Critical Thinking. Procedia - Social and Behavioral Sciences, 70(1), 1-5. https://doi.org/10.1016/j.sbspro.2013.01.031

Alwadai, M. A. (2014). Islamic Teachers' Perceptions of Improving Critical Thinking Skills in Saudi Arabian Elementary Schools (Vol. 3). https://doi.org/10.5539/jel.v3n4p37

Amin, A. M., Duran Corebima, A., Zubaidah, S., \& Mahanal, S. (2017). The Critical Thinking Skills Profile of Preservice Biology Teachers in Animal Physiology. International Conference on Education and Training, 128(1), 179-183. https://doi.org/10.2991/icet-17.2017.30

Arafah, K., Abdullah, H., \& Malago, J. D. (2021). Profile of Critical Thinking Skills on Fluid Mechanics Material by Senior High School Students in Makassar City. Multicultural Education, 7(1), 128-133. https://doi.org/10.5281/zenodo.4445157

Aripin, U., Setiawan, W., \& Hendriana, H. (2019). Critical Thinking Profile of Mathematics in Integral Materials. Journal Of Educational Experts (JEE), 2(2), 97106.

Bezanilla, M. J., Fernández-Nogueira, D., Poblete, M., \& Galindo-Domínguez, H. (2019). Methodologies for teaching-learning critical thinking in higher education: The teacher's view. Thinking Skills and Creativity, 33(1), 1-18. 
https://doi.org/10.1016/j.tsc.2019.100584

Cáceres, M., Nussbaum, M., \& Ortiz, J. (2020). Integrating critical thinking into the classroom: A teacher's perspective. Thinking Skills and Creativity, 37(1). https://doi.org/10.1016/j.tsc.2020.100674

Chan, C. (2019). Using digital storytelling to facilitate critical thinking disposition in youth civic engagement: A randomized control trial. Children and Youth Services Review, 107(2), 1-10. https://doi.org/10.1016/j.childyouth.2019.104522

Cohen, J. (2010). Critical-thinking disposition and profile of critical-thinking disposition for postprofessional graduate athletic training students.

Daryanes, F., Sriyati, S., \& Priyandoko, D. (2016). Implementasi Problem Based Learning untuk Meningkatkan Habits of Mind, Emotional Intelligence, Penguasaan Konsep Siswa Kelas XI Pada Materi Sistem Eksresi dan Sistem Saraf. Seminar Nasional Pendidikan Dan Saintek 2016.

Demirhan, E., \& Köklükaya, A. N. (2014). The Critical Thinking Dispositions of Prospective Science Teachers. Procedia - Social and Behavioral Sciences, 116(1), 1551-1555. https://doi.org/10.1016/j.sbspro.2014.01.433

Fatmawati, A., Zubaidah, S., Mahanal, S., \& Sutopo. (2019). Critical Thinking, Creative Thinking, and Learning Achievement: How They are Related. Journal of Physics: Conference Series, 1417(1), 1-9. https://doi.org/10.1088/1742-6596/1417/1/012070

Gezer, N., Kantek, F., \& Öztürk, N. (2010). Profile and critical thinking levels of nursing students in a health school. Procedia - Social and Behavioral Sciences, 9(1), 20572061. https://doi.org/10.1016/j.sbspro.2010.12.446

Hundial, H. (2020). The Safe Care Framework ${ }^{\mathrm{TM}}$ : A practical tool for critical thinking. Nurse Education in Practice, 48(1), 1-9. https://doi.org/10.1016/j.nepr.2020.102852

Idris, T. (2018). Profil Berpikir Kritis Mahasiswa Program Studi Pendidikan Biologi SeKota Pekanbaru. Bioedusiana, 3(1), 1-7.

Juhji, \& Suardi, A. (2018). Profesi Guru Dalam Mengembangkan Kemampuan Berpikir Kritis Peserta Didik Di Era Globalisasi. Geneologi PAI: Jurnal Pendidikan Agama Islam, 5(1), 16-24.

Laelasari, I., \& Anggraeni, S. (2017). Improving Critical Thinking and Metacognition Ability Using Vee Diagram through Problem-Based Learning of Human Respiratory System. Atlantis Press, 45-51. https://doi.org/10.2991/icmsed-16.2017.16

Laelasari, I., \& Hilmi Adisendjaja, Y. (2018). Mengeksplorasi Kemampuan Berpikir Kritis Dan Rasa Ingin Tahu Siswa Melalui Kegiatan Laboratorium Inquiry Sederhana (Vol. 01). Retrieved from http://journal.stainkudus.ac.id/index.php/Thabiea

Laelasari, I., Sari, N. E., \& Nuhaya, N. (2019). Strategi yang Dapat Dikembangkan Dalam Pembelajaran Laboratorium Biologi. Thabiea : Journal of Natural Science Teaching, 2(1), 29. https://doi.org/10.21043/thabiea.v2i1.4815

Nisa, W. M., Nafiah, Z., \& Wilujeng, I. (2020). Profile of critical thinking skills in student's SMPN 1 Kalipare at topic of substance and its characteristics. Journal of Physics: Conference Series, 1440(1), 1-5. https://doi.org/10.1088/17426596/1440/1/012081

Nurmaulita. (2014). Pembentukan Habits of Mind Siswa Melalui Pembelajaran Salingtemas Pada Mata Pelajaran Fisika. Jurnal Pendidikan Fisika, 3(1), 53-58.

Puspita, I., Kaniawati, I., \& Suwarma, I. R. (2017). Analysis of Critical Thinking Skills on 
the Topic of Static Fluid. Journal of Physics: Conference Series, 895(1), 1-4. https://doi.org/10.1088/1742-6596/895/1/012100

Rahman, A., Rifqiawati, I., Damayanti, S., Lestari, I. D., \& Usman. (2021). Profil Pengembangan Critical Thinking Skills melalui Pembelajaran Scientific Approach di Provinsi Banten. Jurnal Pendidikan Biologi Undiksha, 8(1), 7-18.

Rahman, A., Wahyuni, I., \& Noviani, A. (2018). Profil Kemampuan Berpikir Kritis Dan Kemampuan Metakognitif Siswa Berdasarkan Jenis Kelamin. Jurnal Pendidikan Biologi, 10(1), 28. https://doi.org/10.17977/um052v10i1p28-43

Raikou, N., Karalis, T., \& Ravanis, K. (2017). Implementing an Innovative Method to Develop Critical Thinking Skills in Student Teachers. Acta Didactica Napocensia, 10(2), 21-30. https://doi.org/10.24193/adn.10.2.2

Sk, S., \& Halder, S. (2020). Critical thinking disposition of undergraduate students in relation to emotional intelligence: Gender as a moderator. Heliyon, 6(1), 1-10. https://doi.org/10.1016/j.heliyon.2020.e05477

Supriyati, E., Setyawati, O. I., Purwanti, D. Y., Salsabila, L. S., \& Prayitno, B. A. (2018). Profil Keterampilan Berpikir Kritis Siswa SMA Swasta di Sragen pada Materi Sistem Reproduksi. Bioedukasi: Jurnal Pendidikan Biologi, 11(2), 74-80.

Wiyoko, T. (2019). Analisis Profil Kemampuan Berpikir Kritis Mahasiswa PGSD Dengan Graded Response Models Pada Pembelajaran IPA. Indonesian J. Integr. Sci. Education, 1(1), 25-32. 